\title{
Adiponectin gene rs1501299 polymorphism is associated with increased risk of anterior cruciate ligament rupture
}

\author{
WANVISA UDOMSINPRASERT ${ }^{1}$, PONGSAK YUKTANANDANA ${ }^{2}$, THANATHEP TANPOWPONG $^{2}$, \\ SOMKIAT MALILA $^{3}$, WIROJ JIAMJARASRANGSI ${ }^{4}$ and SITTISAK HONSAWEK ${ }^{2,3}$ \\ ${ }^{1}$ Department of Biochemistry, Faculty of Pharmacy, Mahidol University, Bangkok 10400; \\ ${ }^{2}$ Vinai Parkpian Orthopaedic Research Center, Department of Orthopaedics; ${ }^{3}$ Osteoarthritis and Musculoskeleton \\ Research Unit, Department of Biochemistry; ${ }^{4}$ Department of Preventive and Social Medicine, Faculty of Medicine, \\ King Chulalongkorn Memorial Hospital, Thai Red Cross Society, Chulalongkorn University, Bangkok 10330, Thailand
}

Received November 18, 2018; Accepted December 31, 2018

DOI: $10.3892 /$ br.2018.1180

\begin{abstract}
Anterior cruciate ligament (ACL) rupture is one the most common musculoskeletal soft tissue injuries of the knee. Although the exact mechanisms of this injury remain uncertain, genetic variants have been considered to be an intrinsic risk factor associated with ACL rupture. Therefore, the aim of the present study was to determine whether the adiponectin $+276 \mathrm{G} / \mathrm{T}$ polymorphism is associated with susceptibility to ACL rupture in a Thai population. Genotyping for rs1501299 was conducted in 98 participants with ACL rupture and 95 healthy controls by polymerase chain reaction-restriction fragment length polymorphism analysis. The results demonstrated that the GG genotype and $\mathrm{G}$ allele were significantly associated with an increased risk of $\mathrm{ACL}$ rupture [odds ratio $(\mathrm{OR})=1.91$, $\mathrm{P}=0.026 ; \mathrm{OR}=1.89, \mathrm{P}=0.004]$, whereas the TT genotype was significantly associated with a reduced risk of ACL rupture $(\mathrm{OR}=0.32, \mathrm{P}=0.019)$. Furthermore, ACL injury patients with non-contact sports carrying the GG genotype and $\mathrm{G}$ allele exhibited a significantly higher risk of ACL rupture $(\mathrm{OR}=2.13$, $\mathrm{P}=0.031 ; \mathrm{OR}=1.84, \mathrm{P}=0.029$ ). In addition, overweight patients carrying the GG genotype and $\mathrm{G}$ allele had a significantly
\end{abstract}

Correspondence to: Professor Sittisak Honsawek, Osteoarthritis and Musculoskeleton Research Unit, Department of Biochemistry, Faculty of Medicine, King Chulalongkorn Memorial Hospital, Thai Red Cross Society, Chulalongkorn University, 1873 Rama IV Road Patumwan, Bangkok 10330, Thailand

E-mail: sittisak.h@chula.ac.th

Abbreviations: ACL, anterior cruciate ligament; AMPK, adenosine monophosphate-activated protein kinase; BMI, body mass index, CI, confidence interval; ECM, extracellular matrix; MAPK, mitogen-activated protein kinase; MMPs, matrix metalloproteinases; OR, odds ratio; PCR-RFLP, polymerase chain reaction-restriction fragment length polymorphism; SD, standard deviation; SNPs, single-nucleotide polymorphisms

Key words: anterior cruciate ligament, adiponectin, contact sport, overweight, polymorphisms increased (8-fold) risk of ACL rupture $(\mathrm{OR}=8.00, \mathrm{P}<0.001$; $\mathrm{OR}=5.15, \mathrm{P}<0.001)$, whereas overweight patients with the adiponectin $+276 \mathrm{G} / \mathrm{T}$ GT genotype had a significantly lower risk of ACL rupture $(\mathrm{OR}=0.13, \mathrm{P}<0.001)$. Therefore, the adiponectin $+276 \mathrm{G} / \mathrm{T}$ polymorphism $\mathrm{GG}$ genotype and $\mathrm{G}$ allele were significantly associated with the risk of ACL rupture, particularly in overweight patients. These findings indicate that the adiponectin $+276 \mathrm{G} / \mathrm{T}$ polymorphism may play a role in the development of ACL rupture in the Thai population.

\section{Introduction}

Anterior cruciate ligament (ACL) rupture is one of the most common musculoskeletal soft tissue injuries sustained by athletes (1) and a leading cause of disability due to the development of knee osteoarthritis (2). However, it has been suggested that ACL rupture also commonly occurs during non-contact sports (3). The increasing rates of ACL rupture caused by non-contact events highlight the need to elucidate the molecular mechanisms underlying its pathology. Although the precise etiology of ACL rupture remains unclear, the pathophysiology of this injury is far more complex, with multiple extrinsic and intrinsic risk factors, including genetics (4). Indeed, a familial predisposition has been reported to be involved in ACL injury (5). This has prompted researchers to try and elucidate the possible effects of genetic factors on the development of ACL injury.

Adiponectin, an adipokine secreted into the circulation by white adipose tissue, plays key roles in regulation of glucose and lipid metabolism in addition to insulin sensitivity (6). Apart from its primary functions, adiponectin has also been shown to possess anti-atherogenic and anti-inflammatory properties in different types of cells and tissues $(7,8)$. With such a potent effect-mediated inflammation, adiponectin exerts its additional effects on bone biology and ligament injury, by eliciting the production of matrix metalloproteinases (MMPs) induced by the transduction of a mitogen-activated protein kinase (MAPK) signaling cascade $(9,10)$. Given that MMPs are considered as the main physiological stimulators of extracellular matrix (ECM) degradation and remodeling, it is not surprising that adiponectin has been proposed to be a possible 
mediator of ACL pathology. It has been well established that the biological activities of adiponectin are regulated by numerous factors, including nutritional behavior, physical activity and, notably, genetic factors, such as single-nucleotide polymorphisms (SNPs) within the adiponectin gene (11). Interestingly, one SNP located 276 bp downstream of the translational start site within the adiponectin gene $(+276 \mathrm{G} / \mathrm{T}, \mathrm{rs} 1501299)$ has been reported to be associated with reduced circulating levels of adiponectin and an elevated risk of type 2 diabetes (12). To date, it remains unclear whether the adiponectin $+276 \mathrm{G} / \mathrm{T}$ (rs1501299) polymorphism is associated with the development of ACL injury; however, three common variants within the MMP3 gene have been previously associated with susceptibility to ACL rupture in the Thai population (13). Therefore, it appears likely that DNA sequence variants within the adiponectin gene controlling its biological function-induced MMP activity regulation of ECM homeostasis may be one of contributory factors associated with the risk of ACL rupture.

Although accumulating data indicate that genetic variations of the adiponectin gene are associated with increased risk of several chronic diseases (14), there is limited information on the association of adiponectin polymorphisms with the risk of ACL injury. Accordingly, the present study aimed to investigate whether the adiponectin $+276 \mathrm{G} / \mathrm{T}$ (rs1501299) polymorphism is associated with susceptibility to ACL rupture.

\section{Materials and methods}

Ethics. The study protocol conformed to the ethical standards outlined in the Declaration of Helsinki and was approved by the Ethics Committee on Human Research of the Faculty of Medicine, Chulalongkorn University. All study subjects were fully informed regarding the study protocol and procedures prior to participating in the study. Written informed consent was obtained from all participants.

Study subjects. A total of 98 patients with surgically diagnosed ACL rupture were recruited for the case-control study from the Sports Medicine Clinic, King Chulalongkorn Memorial Hospital (Bangkok, Thailand). In addition, 95 healthy subjects without any self-reported history of ligament or tendon injury were enrolled as controls. Patients with ACL rupture were categorized in terms of the mechanism of ACL injury into those who sustained the injury through contact sports $(n=47)$ and non-contact sports $(n=51)$, according to the American Orthopedic Society for Sports Medicine Classification system (15). Based on their body mass index (BMI) values, ACL patients were also classified into overweight (BMI $\geq 25 \mathrm{~kg} / \mathrm{m}^{2}$, $\mathrm{n}=35)$ and non-overweight (BMI $<25 \mathrm{~kg} / \mathrm{m} 2, \mathrm{n}=63)$.

Genotyping the adiponectin +276 G/Tpolymorphism. Genomic DNA was extracted from peripheral blood leukocytes using a DNA Purifcation kit (GE Healthcare, Buckinghamshire, UK), according to the manufacturer's protocol. Allelic discrimination of the adiponectin $+276 \mathrm{G} / \mathrm{T}$ (rs1501299) polymorphism was performed using polymerase chain reaction-restriction fragment length polymorphism (PCR-RFLP). Extracted DNA was amplified using forward primer 5'-ACA-CTG-ATA-TAAACG-CCA-TGA-A-3' and reverse primer 5'-GCA-GCA-AAG -CCA-AAG-TTT-C-3'. PCR was performed in a final volume of $25 \mu \mathrm{l}$ containing $10 \mathrm{ng}$ DNA template, $20 \mu \mathrm{M}$ primers, $200 \mathrm{mM}$ dNTPs, $25 \mathrm{mM} \mathrm{MgCl}_{2}$ and $0.25 \mathrm{U}$ Taq polymerase (Fermentas, Glen Burine, MD, USA). The thermal cycling conditions for PCR started with a $95^{\circ} \mathrm{C}$ incubation for $10 \mathrm{~min}$, followed by 35 cycles at $95^{\circ} \mathrm{C}$ for $30 \mathrm{sec}$, then $50^{\circ} \mathrm{C}$ for $60 \mathrm{sec}$ and $72^{\circ} \mathrm{C}$ for $60 \mathrm{sec}$, and finally $72^{\circ} \mathrm{C}$ for $7 \mathrm{~min}$. After PCR amplification, adiponectin amplicons (168 bp) were subsequently digested with $2 \mathrm{U} \mathrm{Bgl \textrm {I }}$ in $1 \mathrm{X}$ buffer (New England BioLabs, Ipswich, MA, USA) and incubated at $37^{\circ} \mathrm{C}$ overnight, followed by separation on a $12 \%$ non-denaturing polyacrylamide gel stained with ethidium bromide. DNA fragments derived from enzymatic digestion of adiponectin products were divided into three fragments of the following sizes: $147 \mathrm{bp}$ and $21 \mathrm{bp}$ in homozygotes GG genotype; 168, 147 and $21 \mathrm{bp}$ in heterozygotes GT; and 168 bp in homozygotes TT.

Statistical analysis. All statistical analyses were performed using SPSS statistical software, version 22.0 (IBM Corp., Armonk, NY, USA). Continuous variables, including demographic and clinical data, are expressed as means \pm standard deviation (SD) and were compared between groups using the Student's unpaired t-test. The genotype distribution of adiponectin $+276 \mathrm{G} / \mathrm{T}$ (rs1501299) polymorphism in ACL patients and healthy controls was analyzed to evaluate whether they are in Hardy-Weinberg equilibrium. Genotype and allele frequencies between two groups were analyzed and compared using $\chi^{2}$ or Fisher's exact tests. Genotype- and allele-based odds ratio (OR) and 95\% confidence interval (CI) with adjustment for confounding factors, including age and BMI, were calculated using logistic regression analysis. All statistical tests were based on two-tailed probability, with P-value $<0.05$ considered to indicate statistically significant differences.

\section{Results}

Participant characteristics. The baseline characteristics of ACL patients and healthy controls are summarized in Table I. Of the 193 participants who were enrolled in this study, 98 were surgically diagnosed with ACL and 95 were healthy controls. The mean age at recruitment in ACL patients was significantly higher compared with that in healthy controls $(\mathrm{P}<0.001)$. As expected, the mean BMI values were significantly higher in ACL patients when compared with those in healthy controls $(\mathrm{P}<0.001)$. Among ACL subgroups, there were no significant differences between ACL patients with and without contact sports in terms of age and mean BMI, as illustrated in Table I.

Genotype and allele frequencies of the adiponectin $+276 G / T$ (rs1501299) polymorphism. The genotype and allelic frequencies of adiponectin $+276 \mathrm{G} / \mathrm{T}$ (rs1501299) polymorphism are presented in Table II. The genotype distribution of adiponectin $+276 \mathrm{G} / \mathrm{T}$ (rs1501299) polymorphism fell within the Hardy-Weinberg equilibrium in both ACL patients and healthy controls $(\mathrm{P}=0.84$ and $\mathrm{P}=0.23$, respectively). Individuals with the adiponectin $+276 \mathrm{G} / \mathrm{T}$ (rs1501299) GG genotype had a significantly higher risk of ACL rupture compared with those with the adiponectin $+276 \mathrm{G} / \mathrm{T}$ (rs1501299) GT and TT genotypes $(\mathrm{OR}=1.91,95 \% \mathrm{CI}: 1.04-3.53, \mathrm{P}=0.026)$. Likewise, the adiponectin $+276 \mathrm{G} / \mathrm{T}$ (rs1501299) G allele was significantly associated with a higher risk of ACL rupture $(\mathrm{OR}=1.89$, 
Table I. General characteristics of controls, ACL patients and ACL subgroups.

\begin{tabular}{lccccc}
\hline & & & & \multicolumn{2}{c}{$\begin{array}{c}\text { ACL subgroups based on } \\
\text { mechanism of injury }\end{array}$} \\
\cline { 3 - 6 } Variables & $\begin{array}{c}\text { Controls } \\
(\mathrm{n}=95)\end{array}$ & $\begin{array}{c}\text { ACL patients } \\
(\mathrm{n}=98)\end{array}$ & P-value $^{\mathrm{a}}$ & $\begin{array}{c}\text { Contact sports } \\
(\mathrm{n}=47)\end{array}$ & $\begin{array}{c}\text { Non-contact } \\
\text { sports }(\mathrm{n}=51)\end{array}$ \\
\hline Age $($ years $)$ & $23.2 \pm 5.3$ & $30.6 \pm 8.4$ & $<0.001$ & $29.2 \pm 6.9$ & $31.9 \pm 9.5$ \\
Height $(\mathrm{cm})$ & $167.6 \pm 7.9$ & $171.6 \pm 9.6$ & $<0.001$ & $172.6 \pm 9.6$ & $170.9 \pm 7.0$ \\
Weight $(\mathrm{kg})$ & $63.8 \pm 11.5$ & $70.7 \pm 9.8$ & $<0.001$ & $70.5 \pm 11.5$ & $70.8 \pm 8.5$ \\
BMI $\left(\mathrm{kg} / \mathrm{m}^{2}\right)$ & $22.2 \pm 4.7$ & $23.9 \pm 2.8$ & 0.003 & $23.6 \pm 3.3$ & $24.2 \pm 2.4$ \\
\hline
\end{tabular}

${ }^{\mathrm{a} C}$ Controls vs. ACL patients. ${ }^{\mathrm{b}} \mathrm{ACL}$ patients with contact sports vs. non-contact sports. P-value $<0.05$ indicates statistical significance. The variables are expressed as a mean \pm standard deviation. ACL, anterior cruciate ligament; NS, not significant; BMI, body mass index.

Table II. Genotype and allele frequencies of adiponectin $+276 \mathrm{G} / \mathrm{T}$ polymorphism in ACL patients and controls.

\begin{tabular}{lccc}
\hline Variables & $\begin{array}{c}\text { Controls, }(\%) \\
(\mathrm{n}=95)\end{array}$ & $\begin{array}{c}\text { ACL patients, }(\%) \\
(\mathrm{n}=98)\end{array}$ & $\begin{array}{c}\text { Adjusted OR }^{\mathrm{a}} \\
(95 \% \mathrm{CI})\end{array}$ \\
\hline $\begin{array}{l}\text { Genotype frequencies } \\
\text { GG }\end{array}$ & $40(42.11)$ & $57(58.16)$ & $1.91(1.04-3.53)$ \\
GT & $39(41.05)$ & $35(35.71)$ & $0.80(0.43-1.49)$ \\
TT & $16(16.84)$ & $6(6.12)$ & $0.32(0.11-0.93)$ \\
Allele frequencies & $119(62.63)$ & $149(76.02)$ & $0.026^{\mathrm{b}}$ \\
G & $71(37.37)$ & $47(23.98)$ & $0.019^{\mathrm{c}}$ \\
T & & & $0.004^{\mathrm{d}}$ \\
\hline
\end{tabular}

${ }^{\mathrm{a}}$ Adjusted for age and body mass index. ${ }^{\mathrm{b}} \mathrm{ACL}$ vs. control, GG genotype vs. TT + GT genotypes. ${ }^{\mathrm{c}} \mathrm{ACL}$ vs. control, TT genotype vs. GG + GT genotypes. ${ }^{\mathrm{d} A C L}$ vs. control, G allele vs. T allele. P-value $<0.05$ indicates statistical significance. ACL, anterior cruciate ligament; OR, odds ratio; CI, confidence interval; NS, not significant.

95\% CI: 1.19-3.01, $\mathrm{P}=0.004)$. By contrast, participants with the adiponectin $+276 \mathrm{G} / \mathrm{T}$ (rs1501299) TT genotype had a significantly lower risk of ACL rupture when compared with those with the adiponectin $+276 \mathrm{G} / \mathrm{T}$ (rs1501299) GT and GG genotypes $(\mathrm{OR}=0.32,95 \% \mathrm{CI}$ : $0.11-0.93, \mathrm{P}=0.019)$.

On stratified analysis according to the mechanisms of ACL injury, ACL patients were divided into contact sport and non-contact sport groups. There were no significant differences in the genotype or allele frequencies of adiponectin $+276 \mathrm{G} / \mathrm{T}$ (rs1501299) polymorphism between ACL patients with contact and non-contact sports (Table III). Notably, the GG genotype and $\mathrm{G}$ allele in ACL patients with regards to non-contact sports were significantly associated with an increased risk of ACL rupture $(\mathrm{OR}=2.13,95 \% \mathrm{CI}: 1.06-4.27, \mathrm{P}=0.031$ and $\mathrm{OR}=1.84$, 95\% CI: $1.06-3.21, \mathrm{P}=0.029$, respectively).

We further explored the genotype and allele frequencies of adiponectin $+276 \mathrm{G} / \mathrm{T}$ (rs1501299) polymorphism in a subgroup of ACL patients according to BMI values. The genotype and allele frequencies of adiponectin $+276 \mathrm{G} / \mathrm{T}$ (rs1501299) polymorphism in ACL subgroups based on BMI values are presented in Table IV. Interestingly, we also found that the adiponectin $+276 \mathrm{G} / \mathrm{T}$ (rs1501299) GG genotype was significantly associated with an 8-fold increase in the risk of ACL rupture in overweight patients compared with those with the adiponectin +276G/T (rs1501299) GT and TT genotypes $(\mathrm{OR}=8.00,95 \% \mathrm{CI}: 2.51-27.18, \mathrm{P}<0.001)$. Furthermore, overweight ACL patients with the adiponectin $+276 \mathrm{G} / \mathrm{T}$ (rs1501299) $\mathrm{G}$ allele had a significantly higher risk of ACL rupture $(\mathrm{OR}=5.15,95 \% \mathrm{CI}: 2.06-12.86, \mathrm{P}<0.001)$, whereas overweight patients carrying the adiponectin $+276 \mathrm{G} / \mathrm{T}$ (rs1501299) GT genotype had a significantly decreased risk of ACL rupture compared with those with the adiponectin $+276 \mathrm{G} / \mathrm{T}$ (rs1501299) $\mathrm{GG}$ and TT genotypes $(\mathrm{OR}=0.13$, 95\% CI: 0.04-0.46, P<0.001).

\section{Discussion}

It is generally recognized that ACL rupture is a complex condition associated with various intrinsic and extrinsic risk factors, particularly genetic variations, which have been identified as a cause of ACL injury. However, the exact etiology of ACL rupture has yet to be fully elucidated. Notably, a number of previous studies demonstrated that DNA sequence variants within several genes, such as alphal chain of type I collagen, proteoglycans, growth differentiation factor 5 and MMP3, were reportedly associated with susceptibility to ACL rupture 
Table III. Genotype and allele frequencies of adiponectin $+276 \mathrm{G} / \mathrm{T}$ polymorphism within the ACL subgroups .

\begin{tabular}{|c|c|c|c|c|c|c|c|}
\hline \multirow[b]{2}{*}{ Variables } & \multirow[b]{2}{*}{$\begin{array}{l}\text { Controls, } \mathrm{n}(\%) \\
\quad(\mathrm{n}=95)\end{array}$} & \multicolumn{2}{|c|}{$\begin{array}{l}\text { ACL subgroups based on } \\
\text { mechanism of injury, } \mathrm{n}(\%)\end{array}$} & Model 1 & \multicolumn{2}{|r|}{ Model 2} & \multirow[b]{2}{*}{ P-value } \\
\hline & & $\begin{array}{c}\text { Non-contact } \\
\text { sports } \\
(\mathrm{n}=51)\end{array}$ & $\begin{array}{l}\text { Contact } \\
\text { sports } \\
(\mathrm{n}=47)\end{array}$ & $\begin{array}{l}\text { Adjusted OR }{ }^{\mathrm{a}} \\
\quad(95 \% \mathrm{CI})\end{array}$ & P-value & $\begin{array}{l}\text { Adjusted } \mathrm{OR}^{\mathrm{a}} \\
\quad(95 \% \mathrm{CI})\end{array}$ & \\
\hline \multicolumn{8}{|c|}{ Genotype frequencies } \\
\hline GG & $40(42.11)$ & $31(60.78)$ & $26(55.32)$ & $0.79(0.36-1.79)$ & NS & $2.13(1.06-4.27)$ & $0.031^{\mathrm{b}}$ \\
\hline GT & $39(41.05)$ & $16(31.37)$ & $19(40.43)$ & $1.48(0.65-3.40)$ & NS & $1.52(0.74-3.13)$ & NS \\
\hline $\mathrm{TT}$ & $16(16.84)$ & $4(7.84)$ & $2(4.26)$ & $0.52(0.091-2.99)$ & NS & $0.42(0.13-1.33)$ & NS \\
\hline \multicolumn{8}{|c|}{ Allele frequencies } \\
\hline $\mathrm{G}$ & $119(62.63)$ & $71(75.53)$ & $78(76.47)$ & $0.91(0.47-1.76)$ & NS & $1.84(1.06-3.21)$ & $0.029^{\mathrm{c}}$ \\
\hline $\mathrm{T}$ & $71(37.37)$ & $23(24.47)$ & $24(23.53)$ & & & & \\
\hline
\end{tabular}

Model 1: ACL patients with non-contact sports vs. contact sports. Model 2: Healthy controls vs. ACL patients with non-contact sports. ${ }^{\mathrm{a} A d-}$ justed for age and body mass index. ${ }^{b}$ Healthy controls vs. ACL patients with non-contact sports, GG genotype vs. TT + GT genotypes. ${ }^{c} \mathrm{Healthy}$ controls vs. ACL patients with non-contact sports, G allele vs. T allele. P-value $<0.05$ indicates statistical significance. ACL, anterior cruciate ligament; OR, odds ratio; CI, confidence interval; NS, not significant.

Table IV. Genotype and allele frequencies of adiponectin gene $+276 \mathrm{G} / \mathrm{T}$ polymorphism in overweight and non-overweight ACL patients.

\begin{tabular}{|c|c|c|c|c|}
\hline \multirow[b]{2}{*}{ Variables } & \multicolumn{2}{|c|}{ ACL subgroups based on BMI value $\left(\mathrm{kg} / \mathrm{m}^{2}\right)$} & \multirow[b]{2}{*}{$\begin{array}{l}\text { Adjusted } \mathrm{OR}^{\mathrm{a}} \\
\quad(95 \% \mathrm{CI})\end{array}$} & \multirow[b]{2}{*}{ P-value } \\
\hline & $\begin{array}{c}\text { Overweight }^{\mathrm{e}}, \mathrm{n}(\%) \\
(\mathrm{n}=35)\end{array}$ & $\begin{array}{l}\text { Non-overweight }{ }^{\mathrm{f}}, \mathrm{n}(\%) \\
(\mathrm{n}=63)\end{array}$ & & \\
\hline \multicolumn{5}{|c|}{ Genotype frequencies } \\
\hline GG & $30(85.71)$ & $27(42.86)$ & $8.00(2.51-27.18)$ & $<0.001^{\mathrm{b}}$ \\
\hline GT & $4(11.43)$ & $31(49.21)$ & $0.13(0.04-0.46)$ & $<0.001^{\mathrm{c}}$ \\
\hline $\mathrm{TT}$ & $1(2.86)$ & $5(7.93)$ & $0.34(0.01-3.24)$ & NS \\
\hline \multicolumn{5}{|c|}{ Allele frequencies } \\
\hline G & $64(91.43)$ & 85 (67.46) & $5.15(2.06-12.86)$ & $<0.001^{\mathrm{d}}$ \\
\hline $\mathrm{T}$ & $6(8.57)$ & $41(32.54)$ & & \\
\hline
\end{tabular}

${ }^{\mathrm{a}}$ Adjusted for age and BMI. ${ }^{\mathrm{b}} \mathrm{ACL}$ overweight vs. non-overweight, GG genotype vs. TT + GT genotypes. ${ }^{\mathrm{c} A C L}$ overweight vs. non-overweight, GT genotype vs. GG + TT genotypes. ${ }^{\mathrm{d}} \mathrm{ACL}$ overweight vs. non-overweight, $\mathrm{G}$ allele vs. T allele. ${ }^{\mathrm{e}} \mathrm{BMI} \geq 25$. fBMI $<25$. P-value $<0.05$ indicates statistical significance. ACL, anterior cruciate ligament; BMI, body mass index; OR, odds ratio; CI, confidence interval; NS, not significant.

(13,16-18). As such, investigating genetic variations within specific genes encoding proteins that possibly affect soft tissue injury may help us better understand the mechanisms underlying the pathology of ACL rupture. Therefore, in the present study, we investigated the association of adiponectin $+276 \mathrm{G} / \mathrm{T}$ (rs1501299) polymorphism with ACL injury and observed that the GG genotype of adiponectin $+276 \mathrm{G} / \mathrm{T}$ (rs1501299) was significantly correlated with an increased risk of ACL rupture. This finding suggests that the adiponectin $+276 \mathrm{G} / \mathrm{T}$ (rs1501299) polymorphism may be used as a novel genetic marker for predicting individuals at a high risk of ACL injury.

It is well-known that adiponectin is an adipokine constitutively produced by adipocytes and exerts its multivalent effects, including insulin-sensitizing, enhancing lipid combustion, anti-atherogenic and anti-inflammatory properties, on various cell types through specific signal transduction pathways (19). As regards its beneficial effects on maintaining ligament homeostasis, adiponectin has been demonstrated to ameliorate the response of ligament lesions to wound healing and tissue regeneration (20), thereby establishing the protective role of adiponectin against the development of ACL rupture. However, the underlying mechanisms regulating the effect of adiponectin on ligament injury remain unclear. It is conceivable that the biological functions of adiponectin are affected by numerous factors, particularly genetic, such as polymorphisms within the 
adiponectin gene (11). In particular, among its polymorphisms, the adiponectin $+276 \mathrm{G} / \mathrm{T}$ (rs1501299) polymorphism, which is downstream of the translational start site, potentially alters circulating adiponectin levels $(20,12)$. In this context, we investigated the genetic variations of adiponectin $+276 \mathrm{G} / \mathrm{T}$ (rs1501299) in patients with ACL rupture compared with healthy controls. We observed that the adiponectin $+276 \mathrm{G} / \mathrm{T}$ (rs1501299) GG genotype was significantly associated with a higher risk of ACL rupture. In addition, the adiponectin +276G/T (rs1501299) G allele was significantly associated with an increased risk of ACL rupture.

In accordance with our findings, the GG genotype and $\mathrm{G}$ allele within adiponectin $+276 \mathrm{G} / \mathrm{T}$ (rs1501299) have been previously associated with the risk of multifactorial diseases including type 2 diabetes (12), cardiovascular disease (21), polycystic ovary syndrome (22) and biliary atresia (23). By contrast, several studies demonstrated that the adiponectin +276G/T (rs1501299) TT genotype was commonly observed in control participants who are Japanese (12), Korean (24) and Han Chinese (25). These findings were in agreement with our results revealing that the frequency of the adiponectin $+276 \mathrm{G} / \mathrm{T}$ (rs1501299) TT genotype was significantly higher in controls rather than in ACL patients, suggesting that the TT genotype of the adiponectin $+276 \mathrm{G} / \mathrm{T}$ (rs1501299) polymorphism is associated with a lower risk of ACL rupture. Collectively, the abovementioned findings indicate that DNA sequence variants within the adiponectin $+276 \mathrm{G} / \mathrm{T}$ (rs1501299) polymorphism, particularly with the $\mathrm{G}$ allele, may represent a novel genetic target for predicting the risk of ACL rupture based on its potential association with ACL injury. In fact, it has been established that non-contact rupture is the most common cause of ACL injury, which occurs from the athlete's own movements and does not result from contact with another athlete or objects (15). This mechanism prompts us to consider the hypothesis that intrinsic risk factors, including genetic polymorphisms, may play a potential contributing role in non-contact ACL rupture. To address this issue, we further investigated the association between adiponectin $+276 \mathrm{G} / \mathrm{T}$ (rs1501299) polymorphism and the risk of ACL rupture in patients with non-contact sports. However, the genetic variants within adiponectin $+276 \mathrm{G} / \mathrm{T}$ (rs1501299) did not differ between ACL rupture patients with and without contact sports. This may be attributed to the small sample size of ACL subgroups involving injury mechanisms between patients with and without contact sports. Of note, our additional findings demonstrated that the GG genotype and $\mathrm{G}$ allele within adiponectin $+276 \mathrm{G} / \mathrm{T}$ (rs1501299) in patients with non-contact sports were significantly associated with ACL risk, suggesting that the adiponectin $+276 \mathrm{G} / \mathrm{T}$ (rs1501299) polymorphism, particularly the $\mathrm{G}$ allele, may be an independent risk factor for ACL rupture.

In addition to non-contact mechanism-induced ACL rupture, epidemiological studies also highlighted body weight and BMI as factors for the development and progression of ACL rupture $(26,27)$. In this regard, we assessed the effect of obesity on the connection of adiponectin $+276 \mathrm{G} / \mathrm{T}$ (rs1501299) polymorphism with the risk of ACL rupture and also found that overweight patients carrying the adiponectin gene $+276 \mathrm{G} / \mathrm{T}$ (rs1501299) GG genotype and G allele had a significantly increased risk of ACL rupture. This finding is consistent with a previous investigation, showing that the adiponectin $+276 \mathrm{G} / \mathrm{T}$ (rs1501299) $\mathrm{G}$ allele was associated with obesity in the Swedish (28). It is noteworthy that individuals carrying the adiponectin gene $+276 \mathrm{G} / \mathrm{T}$ (rs1501299) GG genotype and $\mathrm{G}$ allele, particularly overweight subjects, exhibited a significantly higher risk of ACL rupture. In the light of these considerations, the possibility of genetic variations within the adiponectin gene relevant to the susceptibility of ACL injury is of great interest for the development of the adiponectin $+276 \mathrm{G} / \mathrm{T}$ (rs1501299) polymorphism as a genetic biomarker for identifying who are at a greater risk of ACL rupture.

However, the exact mechanisms underlying the association between the adiponectin $+276 \mathrm{G} / \mathrm{T}$ (rs1501299) polymorphism and ACL injury remain elusive. It is tempting to hypothesize that the adiponectin $+276 \mathrm{G} / \mathrm{T}$ (rs1501299) variants located within intron 2 may play a possible role in the regulation of the transcriptional activity of the adiponectin gene. This hypothesis has been attested by a previous study showing that this intronic polymorphism can alter the expression and production of adiponectin (29). Moreover, the adiponectin $+276 \mathrm{G} / \mathrm{T}$ (rs1501299) G allele was reportedly associated with reduced circulating adiponectin levels in a Japanese population (30). However, the TT genotype within adiponectin $+276 \mathrm{G} / \mathrm{T}$ (rs1501299) has been shown to be associated with upregulated adiponectin expression and enhanced physical activity (31). Therefore, it appears possible that the adiponectin $+276 \mathrm{G} / \mathrm{T}$ (rs1501299) GG genotype may suppress the transcriptional and translational expression of adiponectin in patients with ACL rupture, which may lead to the degradation of EMC responsible for soft tissue injury. To support this hypothesis, it was demonstrated that adiponectin induces an increase in the synthesis of MMPs, contributing to the imbalance of the synthesis and degradation of ECM components via the activation of adenosine monophosphate-activated protein kinase (AMPK)/MAPK signaling pathway (10), which may result in ACL injury. These phenomena may help explain why the GG genotype and $\mathrm{G}$ allele within adiponectin $+276 \mathrm{G} / \mathrm{T}$ (rs1501299) were associated with an increased risk of ACL injury.

It should be noted, however, that there were certain limitations to the present study. First, we evaluated genetic variants within the adiponectin gene in ACL rupture patients, but did not measure the transcriptional and translational expression of adiponectin. Therefore, we were unable to determine the effect of genetic variants on the transcriptional and translational activity of adiponectin associated with ACL rupture in these results. Additional investigation involving the production and expression of adiponectin will provide more valuable information on the pathophysiological role of adiponectin in ACL rupture. In addition, this study was a single-center trial with a relatively small number of ACL rupture subjects, which limits its statistical power. For this reason, the sample size of ACL rupture subjects must be increased in order to reach an unequivocal conclusion. Another weakness is the lack of data regarding the association between the adiponectin $+276 \mathrm{G} / \mathrm{T}$ (rs1501299) polymorphism and other specific polymorphisms within the adiponectin gene. It is recommended that further analysis on haplotype should be conducted to elucidate the functional variation associated with adiponectin expression, and the findings may improve our knowledge on the pathways responsible for the association of the adiponectin gene with ACL rupture. 
In summary, the present study provided evidence that the adiponectin $+276 \mathrm{G} / \mathrm{T}$ (rs1501299) GG genotype and G allele were associated with an increased risk of ACL rupture, particularly in overweight subjects. The abovementioned findings indicates that this polymorphism within the adiponectin gene may serve as a genetic candidate for the prediction of the risk of ACL rupture. However, additional investigations in different populations and/or in larger cohorts of ACL patients are warranted to elucidate the definitive association between adiponectin $+276 \mathrm{G} / \mathrm{T}$ (rs1501299) polymorphism and ACL rupture.

\section{Acknowledgements}

The authors gratefully acknowledge the Research Core Facility of the Department of Biochemistry and Chulalongkorn Medical Research Center (ChulaMRC) for kindly providing facilities and Dr Suriyapong Saowaprut for the generous technical assistance. The authors are profoundly thankful to Asst. Prof. Jiraphun Jittikoon for kindly reviewing the manuscript.

\section{Funding}

The present was supported by the Osteoarthritis and Musculoskeleton Research Unit and Ratchadapiseksompotch Fund, Chulalongkorn University.

\section{Availability of data and materials}

Due to ethical concerns, the data of this study are openly available.

\section{Authors' contributions}

WU, SM and SH conceived and designed the experiments. WU and SM performed the experiments and analyzed the data. WU and SH contributed reagents/materials/analysis tools. PY, TT and WJ enrolled the subjects, obtained informed consent, and collected the clinical data. WU and $\mathrm{SH}$ wrote the paper. All authors have reviewed and approved the final version of this manuscript.

\section{Ethics approval and consent to participate}

The study protocol was approved by the Ethics Committee on Human Research of the Faculty of Medicine, Chulalongkorn University. All study subjects were fully informed regarding the study protocol and procedures prior to participating in the study.

\section{Patient consent for publication}

Written informed consent was obtained from all the participants.

\section{Competing interests}

The authors declare that they have no competing interests in in relation to the work described.

\section{References}

1. Sakdejayont $\mathrm{C}$ and Limpaphayom M: Reconstruction of anterior cruciate ligament with artficial ligament (Leed keio). Cases repost. Chula Med J 30: 561-570, 1986.

2. Wangroongsub Y: The anterior cruciate ligament injured knee: Current concepts. Chula Med J 38: 435-450, 1994.

3. Dragoo JL, Braun HJ, Durham JL, Chen MR and Harris AH: Incidence and risk factors for injuries to the anterior cruciate ligament in National Collegiate Athletic Association football: Data from the 2004-2005 through 2008-2009 National Collegiate Athletic Association Injury Surveillance System. Am J Sports Med 40: 990-995, 2012.

4. Hewett TE, Lynch TR, Myer GD, Ford KR, Gwin RC and Heidt RS Jr: Multiple risk factors related to familial predisposition to anterior cruciate ligament injury: Fraternal twin sisters with anterior cruciate ligament ruptures. Br J Sports Med 44: 848-855, 2010.

5. Flynn RK, Pedersen CL, Birmingham TB, Kirkley A, Jackowski D and Fowler PJ: The familial predisposition toward tearing the anterior cruciate ligament: A case control study. Am J Sports Med 33: 23-28, 2005.

6. Masaki T, Chiba S, Tatsukawa H, Yasuda T, Noguchi H, Seike M and Yoshimatsu H: Adiponectin protects LPS-induced liver injury through modulation of TNF-alpha in KK-Ay obese mice. Hepatology 40: 177-184, 2004.

7. Lira FS, Rosa JC, Pimentel GD, Seelaender M, Damaso AR, Oyama LM and do Nascimento CO: Both adiponectin and interleukin-10 inhibit LPS-induced activation of the NF- $\mathrm{BB}$ pathway in 3T3-L1 adipocytes. Cytokine 57: 98-106, 2012.

8. Tsatsanis C, Zacharioudaki V, Androulidaki A, Dermitzaki E, Charalampopoulos I, Minas V, Gravanis A and Margioris AN: Adiponectin induces TNF-alpha and IL-6 in macrophages and promotes tolerance to itself and other pro-inflammatory stimuli. Biochem Biophys Res Commun 335: 1254-1263, 2005.

9. Nawrocki AR and Scherer PE: The delicate balance between fat and muscle: Adipokines in metabolic disease and musculoskeletal inflammation. Curr Opin Pharmacol 4: 281-289, 2004.

10. Iwayama T, Yanagita M, Mori K, Sawada K, Ozasa M, Kubota M, Miki K, Kojima Y, Takedachi M, Kitamura M, et al: Adiponectin regulates functions of gingival fibroblasts and periodontal ligament cells. J Periodontal Res 47: 563-571, 2012.

11. Shehzad A, Iqbal W, Shehzad O and Lee YS: Adiponectin: Regulation of its production and its role in human diseases. Hormones (Athens) 11: 8-20, 2012.

12. Hara K, Boutin P, Mori Y, Tobe K, Dina C, Yasuda K, Yamauchi T, Otabe S, Okada T, Eto K, et al: Genetic variation in the gene encoding adiponectin is associated with an increased risk of type 2 diabetes in the Japanese population. Diabetes 51: 536-540, 2002.

13. Malila S, Yuktanandana P, Saowaprut S, Jiamjarasrangsi W and Honsawek S: Association between matrix metalloproteinase-3 polymorphism and anterior cruciate ligament ruptures. Genet Mol Res 10: 4158-4165, 2011.

14. Menzaghi C, Ercolino T, Di Paola R, Berg AH, Warram JH, Scherer PE, Trischitta V and Doria A: A haplotype at the adiponectin locus is associated with obesity and other features of the insulin resistance syndrome. Diabetes 51: 2306-2312, 2002.

15. Marshall SW, Padua D and McGrath M: Incidence of ACL injuries. In: Hewett TE, Schultz SJ and Griffin LY: Understanding and preventing noncontact ACL injuries.Champaign, IL. Human Kinetics 5-30, 2007.

16. Posthumus M, September AV, Keegan M, O'Cuinneagain D, Van der Merwe W, Schwellnus MP and Collins M: Genetic risk factors for anterior cruciate ligament ruptures: COL1A1 gene variant. Br J Sports Med 43: 352-356, 2009.

17. Mannion S, Mtintsilana A, Posthumus M, van der Merwe W, Hobbs H, Collins M and September AV: Genes encoding proteoglycans are associated with the risk of anterior cruciate ligament ruptures. Br J Sports Med 48: 1640-1646, 2014.

18. Chen B, Li B, Qi YJ, Tie K and Chen LB: Association study between growth differentiation factor 5 polymorphism and non-contact anterior cruciate ligament rupture in Chinese Han population. Int J Clin Exp Med 8: 22484-22490, 2015.

19. Ryo M, Nakamura T, Kihara S, Kumada M, Shibazaki S, Takahashi M, Nagai M, Matsuzawa Y and Funahashi T: Adiponectin as a biomarker of the metabolic syndrome. Circ J 68: 975-981, 2004. 
20. Sepilian V and Nagamani M: Adiponectin levels in women with polycystic ovary syndrome and severe insulin resistance. J Soc Gynecol Investig 12: 129-134, 2005.

21. Filippi E, Sentinelli F, Romeo S, Arca M, Berni A, Tiberti C, Verrienti A, Fanelli M, Fallarino M, Sorropago G, et al: The adiponectin gene $\mathrm{SNP}+276 \mathrm{G}>\mathrm{T}$ associates with early-onset coronary artery disease and with lower levels of adiponectin in younger coronary artery disease patients (age $<$ or $=50$ years). J Mol Med (Berl) 83: 711-719, 2005.

22. Li L, Yun JH, Lee JH, Song S, Choi BC and Baek KH: Association study of $+45 \mathrm{G} 15 \mathrm{G}(\mathrm{T} / \mathrm{G})$ and $+276(\mathrm{G} / \mathrm{T})$ polymorphisms in the adiponectin gene in patients with polycystic ovary syndrome. Int J Mol Med 27: 283-287, 2011.

23. Udomsinprasert W, Tencomnao T, Honsawek S, Anomasiri W, Vejchapipat P, Chongsrisawat V and Poovorawan Y: +276 G/T single nucleotide polymorphism of the adiponectin gene is associated with the susceptibility to biliary atresia. World J Pediatr 8: 328-334, 2012

24. Kang ES, Park SY, Kim HJ, Ahn CW, Nam M, Cha BS, Lim SK, Kim KR and Lee HC: The influence of adiponectin gene polymorphism on the rosiglitazone response in patients with type 2 diabetes. Diabetes Care 28: 1139-1144, 2005.

25. Wang Y, Zhang D, Liu Y, Yang Y, Zhao T, Xu J, Li S, Zhang Z, Feng G, He L, et al: Association study of the single nucleotide polymorphisms in adiponectin-associated genes with type 2 diabetes in Han Chinese. J Genet Genomics 36: 417-423, 2009.

26. Uhorchak JM, Scoville CR, Williams GN, Arciero RA, St Pierre P and Taylor DC: Risk factors associated with noncontact injury of the anterior cruciate ligament: A prospective four-year evaluation of 859 West Point cadets. Am J Sports Med 31: 831-842, 2003
27. Bahr R and Krosshaug T: Understanding injury mechanisms: A key component of preventing injuries in sport. Br J Sports Med 39: 324-329, 2005.

28. Vasseur F, Helbecque N, Dina C, Lobbens S, Delannoy V, Gaget S, Boutin P, Vaxillaire M, Leprêtre F, Dupont S, et al: Single-nucleotide polymorphism haplotypes in the both proximal promoter and exon 3 of the APM1 gene modulate adipocyte-secreted adiponectin hormone levels and contribute to the genetic risk for type 2 diabetes in French Caucasians. Hum Mol Genet 11: 2607-2614, 2002.

29. Pollin TI, Tanner K, O'connell JR, Ott SH, Damcott CM, Shuldiner AR, McLenithan JC and Mitchell BD: Linkage of plasma adiponectin levels to $3 q 27$ explained by association with variation in the APM1 gene. Diabetes 54: 268-274, 2005.

30. Katakami N, Kaneto H, Matsuoka TA, Takahara M, Maeda N, Shimizu I, Ohno K, Osonoi T, Kawai K, Ishibashi F, et al: Adiponectin G276T gene polymorphism is associated with cardiovascular disease in Japanese patients with type 2 diabetes. Atherosclerosis 220: 437-442, 2012.

31. Yu Z, Ye X, Wang J, Qi Q, Franco OH, Rennie KL, Pan A, Li H, Liu Y, Hu FB, et al: Associations of physical activity with inflammatory factors, adipocytokines, and metabolic syndrome in middle-aged and older chinese people. Circulation 119: 2969-2977, 2009 